\section{Access to safe water and personal hygiene practices in the Kulandia Refugee Camp (Jerusalem)}

\author{
Mohamad Issa, ${ }^{1}$ Michael McHenry, ${ }^{2}$ \\ Abdul Aziz Issa, ${ }^{3}$ \\ R. Alexander Blackwood' \\ 'Department of Pediatrics, Division of \\ Infectious Diseases, Office of Health \\ Equity and Inclusion, University of \\ Michigan Medical School, Ann Arbor; \\ 'University of Michigan School of Public \\ Health, Ann Arbor; ${ }^{3}$ Eastern Michigan \\ University, Ypsilanti, MI, USA
}

\section{Abstract}

Diarrheal illness, frequently associated with fecal-oral transmission, is one of the leading causes of death worldwide. It is commonly preventable through the implementation of safe water practices. This experiment concerns how to best implement safe water practices in a quasi-permanent refugee camp setting with limited ability for structural changes. Specifically, we explore how health promotion activities that help identify target groups for hygiene interventions can play a role in disease prevention. An anonymous survey was conducted at the United Nations Relief and Works Agency Health Clinic in the Kulandia refugee camp to assess the safe water and personal hygiene practices. Demographic and social characteristics, accessible water and personal hygiene characteristics, and gastrointestinal (GI) burden for individuals and their households were assessed. A total of 96 individuals were enrolled; 62 females and 34 males. Approximately 58\% of the sample had soap available and washed hands before and after eating and when preparing food. Piped water was the main source of drinking water (62\%), while $31 \%$ of our sample utilized tanker-trucks. $93 \%$ of participants had access to toilet facilities, with $86 \%$ of these facilities being private households. $55 \%$ practice extra water hygiene measures on their household drinking water source. $51.3 \%$ considered vendor cleanliness when they were buying food. $51 \%$ had received formal health education. $68.8 \%$ had been taught by their parents, but only $55.2 \%$ were teaching their children and $15.6 \%$ had consistent access to a health professional for hygiene inquiries. Individual variables and hygiene practices associated with lower rates of diarrheal illnesses included having water piped into the home, proper hand washing, adequate soap availability, proper consideration of vendor cleanliness, higher income, levels of education, health hygiene education, and having access to healthcare professions to discuss hygiene related matters. This is the first study to assess the water and personal hygiene practices at the Kulandia refugee ramp. This study demonstrates that hygiene education and better practices are closely associated with the rate at which individuals and households suffer from diarrheal illnesses within the Kulandia refugee camp. There are significant hygiene deficits in the camp, which likely result from a lack of formal hygiene education and a lack of awareness concerning the connection between diarrheal illness and hygiene. With respect to practices, our results elucidate several areas where basic, communal programming - including lessons on appropriate hand washing and food preparation - will likely improve hygiene practices and decrease overall GI burden.

\section{Introduction}

The Palestinian refugee population is one of the oldest and largest populations of refugees in the world. ${ }^{1}$ In 1948, with the creation of the state of Israel, more than 700,000 Palestinians fled their homes. Four generations later, Palestinian refugees remain displaced. The population of Palestinian refugees has grown considerably, estimated now to be greater than 6 million people. Generally, Palestinian refugee camps are poor, overcrowded and lack adequate basic infrastructure. ${ }^{2-4}$ In 1948 the United Nations established the United Nations Relief for Palestine Refugees (UNRPR) agency to address the issues pertinent to Palestinian refugees. This agency was replaced a year later with the United Nations Relief and Works Agency (UNRWA). UNRWA is charged with navigating the different environments in which refugees reside to provide services in health, education, relief and social services, micro-credit financing, infrastructural support and emergency aid to these communities. ${ }^{5,6}$

Palestinian refugees face a multitude of health challenges deriving from factors associated with their living conditions, including overcrowded housing, inadequate or non-existent public infrastructure, and a deeply underresourced social infrastructure.,7 Globally, infectious diseases are a major cause of morbidity and mortality in developing countries, accounting for $43 \%$ of the total global disease burden, with acute respiratory infections and diarrheal illnesses being the most common manifestations in children. In the West Bank, the primary causes of death in infants less than one year old are infectious diseases, specifically both acute respiratory infections and diarrheal disease. ${ }^{8}$ The incidence of
Correspondence: Roland Alexander Blackwood, Division of Pediatric Infectious Diseases, Institutional Review Board, D5101 Medical Professional Building, SPC 5718,1500 E. Medical Center Drive, The University of Michigan, Ann Arbor, MI 48109-5718, USA.

Tel.: +1.734.763.2440 - Fax: +1.734.232.3859.

E-mail: rab@med.umich.edu

Key words: Health hygiene; international research; Palestine; refugee.

Contributions: MI, RAB, AI, conceived and designed the experiments; MI, AI, performed the experiments; $\mathrm{MI}, \mathrm{AI}, \mathrm{MMH}, \mathrm{RAB}$, analyzed the data; $\mathrm{RAB}$, contributed reagents/materials/analysis tools; $\mathrm{MI}, \mathrm{AI}, \mathrm{RAB}, \mathrm{MMH}$, wrote and reviewed the paper.

Conflict of interest: the authors declare no potential conflict of interest.

Received for publication: 27 May 2015.

Revision received: 21 July 2015.

Accepted for publication: 31 August 2015.

This work is licensed under a Creative Commons Attribution NonCommercial 3.0 License (CC BYNC 3.0).

(C) Copyright M. Issa et al., 2015

Licensee PAGEPress, Italy

Infectious Disease Reports 2015; 7:6040

doi:10.4081/idr.2015.6040

reported cases of infectious diarrheal illness is 607 per 100,000 . In a random survey of children in the West Bank, 14 percent of children under 5 years of age had an episode of diarrhea in the 2 weeks prior to the survey. ${ }^{8} \mathrm{~A}$ United Nations Children's Fund (UNICEF) study reported that 71 percent of UNRWA schoolchildren in Gaza had a parasitic infection and 14 percent had more than one type of parasite. ${ }^{8}$ These infections are frequently associated with fecal-oral transmission; lower scores on measures of personal hygiene practices are associated with higher rates of infections across a variety of geographic, political, and socioeconomic contexts. Many of these infections could be prevented through the implementation of safe water practices including sewage waste management and improved personal and water hygiene practices. ${ }^{9} \mathrm{~A}$ World Health Organization (WHO) task force has prioritized population personal and domestic hygiene, which includes the establishment of safe drinking and cooking water as well as good hand washing practices. ${ }^{9}$

The Kulandia refugee camp is located in the West Bank near East Jerusalem, and has been under formal Israeli military occupation since 1967 . The camp is densely populated, with over 11,000 registered refugees on 0.35 square kilometers of land. Almost one in five residents liv- 
ing at the camp are unemployed. ${ }^{10}$ According to the results of the Community Survey conducted by the Applied Research InstituteJerusalem (ARIJ) in 2010, 97\% of the homes were connected to the sewage system, but there $3 \%$ of housing units utilized cesspits. The sewage system, originally designed only for liquid waste, is inadequate for the needs of the camp. New connections to the sewage system is usually done by camp residents themselves, often inadequately, leading to frequent leakage. ${ }^{10}$ The untreated wastewater collected through the sewerage system and cesspits is released into the local environment, without environmental or health considerations. ${ }^{11}$ In 2007 the Jerusalem Water Company replaced the water network without coordinating with UNRWA, which resulted in the destruction of the camp's paved roads and further worsened camp conditions. ${ }^{10}$ The structural limitations highlight the need to maximize individual hygiene practices through community health promotion activities. UNRWA currently offers various health, education and social safety-net programs at Kulandia. ${ }^{12}$ These health education programs were established to ensure that UNRWA healthcare and sanitation workers have a clear understanding of proper hygiene practices. ${ }^{13}$ They are not offered in schools, and only informal classes are held on health subjects in health centers. ${ }^{13}$ Research available on Palestinian refugees is limited and, to the authors' knowledge, there are no studies that examine the personal and water hygiene practices as they relate to the development of respiratory and diarrheal disease in this population. We investigated the safe water and personal hygiene practices in the Kulandia Refugee camp, with an analytical focus on the relationship between hygiene practices and education relative to gastrointestinal (GI) burden as measured by diarrheal and emesis episodes. The associations between personal and water hygiene practices and GI burden have already been established. ${ }^{14,15}$ The main objective of this study is two-fold. First, the authors aim to demonstrate that the relationships between GI burden and hygiene practices are consistent in a quasi-permanent multigenerational refugee camp. Second, the authors aim to identify target groups and interventions for health promotion with the goals of disease prevention. Understanding where Palestinian refugee adults lack in essential health care knowledge would provide targets for effective intervention, as children frequently model parental behavior. We hypothesized that diarrheal and emesis burden in the camp were associated with poor safe water and personal hygiene practices. We also hypothesize that there exist target groups with significantly worse hygiene practices that could be the focus of community health programs.

Table 1. Total distribution of water/personal hygiene education variables of interest and distribution of these same variables across individual and household gastrointestinal cases (case is defined as having 2 or more episodes of diarrheal and emesis).

\begin{tabular}{|c|c|c|c|c|c|c|}
\hline \multirow[t]{2}{*}{ Variable } & \multicolumn{2}{|c|}{ Totals } & \multicolumn{3}{|c|}{ Composite GI score [N (\%)] } & \multirow[b]{2}{*}{$\mathbf{P}$} \\
\hline & $\mathbf{N}$ & $\%$ & Low & Medium & High & \\
\hline Total & 96 & 100 & $42(44)$ & $19(20)$ & $35(36)$ & \\
\hline Age (mean) & $31.7 \pm 9.1$ & & & & & \\
\hline \multicolumn{3}{|l|}{ Sex } & & & & 0.12 \\
\hline Female & 62 & 64.6 & $23(37)$ & $12(19)$ & $27(44)$ & \\
\hline Male & 34 & 35.4 & $19(56)$ & $7(21)$ & $8(24)$ & \\
\hline \multicolumn{3}{|l|}{ Education level } & & & & 0.49 \\
\hline$\leq 8$ th grade & 48 & 50.0 & $18(38)$ & $11(23)$ & $19(40)$ & \\
\hline Some or high school graduate & 25 & 26.0 & $14(56)$ & $5(20)$ & $6(24)$ & \\
\hline Some or college graduate & 23 & 24.0 & $10(43)$ & $3(13)$ & $10(43)$ & \\
\hline \multicolumn{2}{|l|}{ Annual income (USD) } & & & & & 0.22 \\
\hline$<2000$ & 32 & 33.3 & $17(53)$ & $6(19)$ & $9(28)$ & \\
\hline $2000-3000$ & 36 & 37.5 & $13(36)$ & $5(14)$ & $18(50)$ & \\
\hline$>3000$ & 28 & 29.2 & $12(43)$ & $8(29)$ & $8(29)$ & \\
\hline \multicolumn{2}{|l|}{ Household water source* } & & & & & 0.14 \\
\hline Piped into dwelling & 46 & 47.9 & $24(52)$ & $7(15)$ & $15(33)$ & \\
\hline Piped into yard/plot & 11 & 11.5 & $5(45)$ & $5(45)$ & $1(9)$ & \\
\hline Tanker-truck & 30 & 31.3 & $11(37)$ & $6(20)$ & $13(43)$ & \\
\hline \multicolumn{2}{|l|}{ Drinking water source* } & & & & & 0.01 \\
\hline Piped into dwelling & 45 & 46.9 & $26(56)$ & $5(11)$ & $14(31)$ & \\
\hline Piped into yard/plot & 14 & 14.6 & $6(43)$ & $6(43)$ & $2(14)$ & \\
\hline Tanker-truck & 30 & 31.3 & $10(33)$ & $7(23)$ & $13(43)$ & \\
\hline \multicolumn{2}{|l|}{ Parents provided hygiene education } & & & & & 0.17 \\
\hline Yes & 66 & 68.7 & $33(50)$ & $11(17)$ & $22(33)$ & \\
\hline No & 30 & 31.3 & $9(30)$ & $8(27)$ & $13(43)$ & \\
\hline \multicolumn{2}{|l|}{ Received formal hygiene education } & & & & & 0.76 \\
\hline Yes & 49 & 51.0 & $20(41)$ & $11(22)$ & $18(37)$ & \\
\hline No & 47 & 49.0 & $22(47)$ & $8(17)$ & $17(36)$ & \\
\hline \multicolumn{2}{|l|}{ Teach children hygienic practices } & & & & & 0.14 \\
\hline Yes & 53 & 55.2 & $28(53)$ & $7(13)$ & $18(34)$ & \\
\hline No & 23 & 24.0 & $7(30)$ & $5(22)$ & $11(48)$ & \\
\hline Sometimes & 20 & 20.8 & $7(35)$ & $7(35)$ & $6(30)$ & \\
\hline \multicolumn{2}{|c|}{ Access to health professional for hygiene advice } & & & & & 0.54 \\
\hline Yes & 15 & 15.6 & $8(53)$ & $3(20)$ & $4(27)$ & \\
\hline No & 56 & 58.3 & $23(41)$ & $9(16)$ & $24(43)$ & \\
\hline Sometimes & 25 & 26.1 & $11(44)$ & $7(28)$ & $7(28)$ & \\
\hline
\end{tabular}

These two questions had additional response choices that were not included on this table due to very low response numbers. As such, the percentages listed do not total to $100 \%$. 


\section{Materials and Methods}

To assess the safe water and personal hygiene practices in Kulandia, an anonymous survey was conducted at the UNRWA Health Clinic. Participants were recruited randomly from the camp clinic visitors by offering enrollment into the study to every third visitor seen in the clinic. Demographic and social characteristics, along with accessible water and personal hygiene characteristics, including both practices and education, were assessed. Four specific survey questions were used to measure the outcomes of interest, with two questions dedicated to both individual and household GI burden (emesis and diarrhea). Diarrhea was defined as a significant elevation in stool movement relative to a subject's normal bowel habits. The authors decided on using this broad definition to ensure capturing all cases that locals would define as diarrheal. The SAS 9.4 statistical software package was used to calculate descriptive statistics and perform chi squared analyses to determine the effects of patient variables on individual and household GI burden, as measured by diarrhea and emesis episodes. A new variable, termed composite GI score, was created to consolidate the survey questions regarding household emesis and diarrhea into a single measure of household GI burden. This was done with the goal of providing a crude estimate of waterborne disease, which generally is characterized by concomitant emesis and diarrhea. ${ }^{16}$ High composite GI score was defined as having 6 or more total cases of household diarrheal and emesis episodes in the past year, with at least 2 episodes in each category. Moderate and low composite GI score categories were defined as 3-5 episodes and less than 3 episodes, respectively. Particular patient covariates of interest were selected to test their association with this new outcome variable using chi-square analysis (Table 1). Access to health professionals to address hygiene related issues was defined as access to health education staff outside of the specific health clinic from which the subjects were recruited. The goal was to assess resources in the general community given that clinic patients were scheduled to be seeing healthcare professionals theoretically trained in best hygiene practices. This study was determined to be exempt from Institutional Review Board (IRB) review at the University of Michigan in accordance with Federal regulations.

Table 2. Total distribution of demographic and water/personal hygiene practice variables of interest and distribution of these same variables across individual and household gastrointestinal cases (case is defined as having 2 or more episodes of diarrheal and emesis; $\mathrm{N}=96$ ).

\begin{tabular}{|c|c|c|c|c|c|c|c|c|c|c|}
\hline Variable & $\mathbf{N}$ & $\%$ & $\begin{array}{c}\text { Individual } \\
\text { diarrhea (\%) }\end{array}$ & $P$ & $\begin{array}{c}\text { Individual } \\
\text { vomiting (\%) }\end{array}$ & $P$ & $\begin{array}{l}\text { Household } \\
\text { diarrhea (\%) }\end{array}$ & $\mathbf{P}$ & $\begin{array}{c}\text { Household } \\
\text { vomiting (\%) }\end{array}$ & $\mathbf{P}$ \\
\hline $\begin{array}{l}\text { Sex* }^{*} \\
\quad \text { Female } \\
\quad \text { Male }\end{array}$ & $\begin{array}{l}62 \\
34\end{array}$ & $\begin{array}{l}64.6 \\
35.4\end{array}$ & $\begin{array}{c}36(58) \\
7(21)\end{array}$ & 0 & $\begin{array}{l}51(82) \\
18(53)\end{array}$ & 0 & $\begin{array}{l}35(56) \\
15(44)\end{array}$ & 0.25 & $\begin{array}{l}49(79) \\
19(56)\end{array}$ & 0.02 \\
\hline $\begin{array}{l}\text { Education level } \\
\text { s 8th grade } \\
\text { Some or high school graduate } \\
\text { Some or college graduate }\end{array}$ & $\begin{array}{l}48 \\
25 \\
23\end{array}$ & $\begin{array}{l}50.0 \\
26.0 \\
24.0\end{array}$ & $\begin{array}{l}30(63) \\
5(20) \\
8(35)\end{array}$ & 0 & $\begin{array}{l}42(88) \\
13(52) \\
14(61)\end{array}$ & 0 & $\begin{array}{l}26(54) \\
11(44) \\
13(56)\end{array}$ & 0.63 & $\begin{array}{l}35(73) \\
15(60) \\
18(78)\end{array}$ & 0.34 \\
\hline $\begin{array}{l}\text { Annual income (USD) } \\
\quad<2000 \\
\quad 2000-3000 \\
>3000\end{array}$ & $\begin{array}{l}32 \\
36 \\
28\end{array}$ & $\begin{array}{l}33.3 \\
37.5 \\
29.2\end{array}$ & $\begin{array}{l}15(47) \\
19(53) \\
9(32)\end{array}$ & 0.25 & $\begin{array}{l}22(69) \\
29(81) \\
18(64)\end{array}$ & 0.32 & $\begin{array}{l}14(44) \\
21(58) \\
15(54)\end{array}$ & 0.48 & $\begin{array}{l}21(65) \\
26(72) \\
21(75)\end{array}$ & 0.71 \\
\hline $\begin{array}{l}\text { Household water source } \\
\text { Piped into dwelling } \\
\text { Piped into yard/plot } \\
\text { Tanker-truck }\end{array}$ & $\begin{array}{l}46 \\
11 \\
30\end{array}$ & $\begin{array}{l}47.9 \\
11.5 \\
31.3\end{array}$ & $\begin{array}{l}10(22) \\
9(82) \\
16(53)\end{array}$ & 0 & $\begin{array}{l}26(57) \\
10(91) \\
25(83)\end{array}$ & 0.06 & $\begin{array}{c}22(48) \\
6(55) \\
15(50)\end{array}$ & 0.70 & $\begin{array}{l}29(63) \\
8(73) \\
24(80)\end{array}$ & 0.34 \\
\hline $\begin{array}{l}\text { Drinking water source } \\
\text { Piped into dwelling } \\
\text { Piped into yard/plot } \\
\text { Tanker-truck }\end{array}$ & $\begin{array}{l}45 \\
14 \\
30\end{array}$ & $\begin{array}{l}46.9 \\
14.6 \\
31.3\end{array}$ & $\begin{array}{c}12(27) \\
9(64) \\
15(50)\end{array}$ & 0 & $\begin{array}{l}25(56) \\
12(86) \\
25(83)\end{array}$ & 0.06 & $\begin{array}{c}20(44) \\
8(57) \\
15(50)\end{array}$ & 0.27 & $\begin{array}{c}29(64) \\
9(64) \\
24(80)\end{array}$ & 0.35 \\
\hline $\begin{array}{l}\text { Parents provided hygiene education* } \\
\text { Yes } \\
\text { No }\end{array}$ & $\begin{array}{l}66 \\
30 \\
\end{array}$ & $\begin{array}{l}68.7 \\
31.3 \\
\end{array}$ & $\begin{array}{l}24(36.4) \\
19(63.3)\end{array}$ & 0.01 & $\begin{array}{l}44(66.7) \\
25(83.3)\end{array}$ & 0.09 & $\begin{array}{c}33(50) \\
17(56.7)\end{array}$ & 0.54 & $\begin{array}{l}42(63.6) \\
26(86.7)\end{array}$ & 0.03 \\
\hline $\begin{array}{l}\text { Received formal hygiene education* } \\
\text { Yes } \\
\text { No }\end{array}$ & $\begin{array}{l}49 \\
47\end{array}$ & $\begin{array}{l}51.0 \\
49.0\end{array}$ & $\begin{array}{l}19(38.8) \\
24(51)\end{array}$ & 0.23 & $\begin{array}{l}34(69.4) \\
35(74.5)\end{array}$ & 0.58 & $\begin{array}{c}24(49) \\
26(55.3)\end{array}$ & 0.53 & $\begin{array}{l}35(71.4) \\
33(70.2)\end{array}$ & 0.90 \\
\hline $\begin{array}{l}\text { Teach children hygienic practices* } \\
\text { Yes } \\
\text { No } \\
\text { Sometimes }\end{array}$ & $\begin{array}{l}53 \\
23 \\
20\end{array}$ & $\begin{array}{l}55.2 \\
24.0 \\
20.8\end{array}$ & $\begin{array}{l}15(28) \\
18(78) \\
10(50)\end{array}$ & 0 & $\begin{array}{l}33(62) \\
22(96) \\
14(70)\end{array}$ & 0.01 & $\begin{array}{l}24(45) \\
16(70) \\
10(50)\end{array}$ & 0.15 & $\begin{array}{l}33(62) \\
21(91) \\
14(70)\end{array}$ & 0.03 \\
\hline $\begin{array}{l}\text { Access to health professional for hygiene advice* } \\
\text { Yes } \\
\text { No } \\
\text { Sometimes }\end{array}$ & $\begin{array}{l}15 \\
56 \\
25\end{array}$ & $\begin{array}{l}15.6 \\
58.3 \\
26.1\end{array}$ & $\begin{array}{c}5(33) \\
24(43) \\
14(56)\end{array}$ & 0.34 & $\begin{array}{l}8(53) \\
40(71) \\
21(84)\end{array}$ & 0.12 & $\begin{array}{c}8(53) \\
31(55) \\
11(44)\end{array}$ & 0.66 & $\begin{array}{c}8(53) \\
41(73) \\
19(76)\end{array}$ & 0.27 \\
\hline
\end{tabular}

P-values were calculated using chi-square and Fisher's exact tests of association. They indicate respectively the association between: individual episodes of diarrhea and relevant exposure variables, individual episodes of vomiting and relevant exposure variables, household diarrheal cases and relevant exposure variables, household vomiting cases and relevant exposure variables. ${ }^{*}$ Odds ratios for variable of interest could be found in Table 3. \#These two survey questions had additional response choices that were not included on this table due to very low response numbers. As such, the percentages listed do not total to $100 \%$. 


\section{Results}

A total of 96 individuals were enrolled in the study; 62 females and 34 males. The average age of the respondents was $31.7 \pm 9$ years. $50 \%$ of the study participants had less than an $8^{\text {th }}$ grade education. Amongst our study participants, women were better educated than men, with only $11.8 \%$ of them having less than $8^{\text {th }}$ grade education compared with $69.4 \%$ of the men $(\mathrm{P}<0.05)$. Seventy percent of the study subjects earned $<3000$ Dollars a year. The results are summarized in Tables 2 and 3.
Regarding camp personal health hygiene practices, approximately $58 \%$ of the population had soap available and practiced adequate hand washing with meals (Washed hands before and after eating; washed hands when preparing food; Figure 1A). As demonstrated in Figure 2, In each category women were more likely to have better hygiene practices with lower GI burden as measured by emesis $(\mathrm{P}<0.05)$ and diarrhea $(\mathrm{P}<0.05)$ relative to men. Most of the camp's residents had access to toilet facilities (93\%), with private facilities in most households (86\%). Only $51.3 \%$ of the respondents considered vendor cleanliness
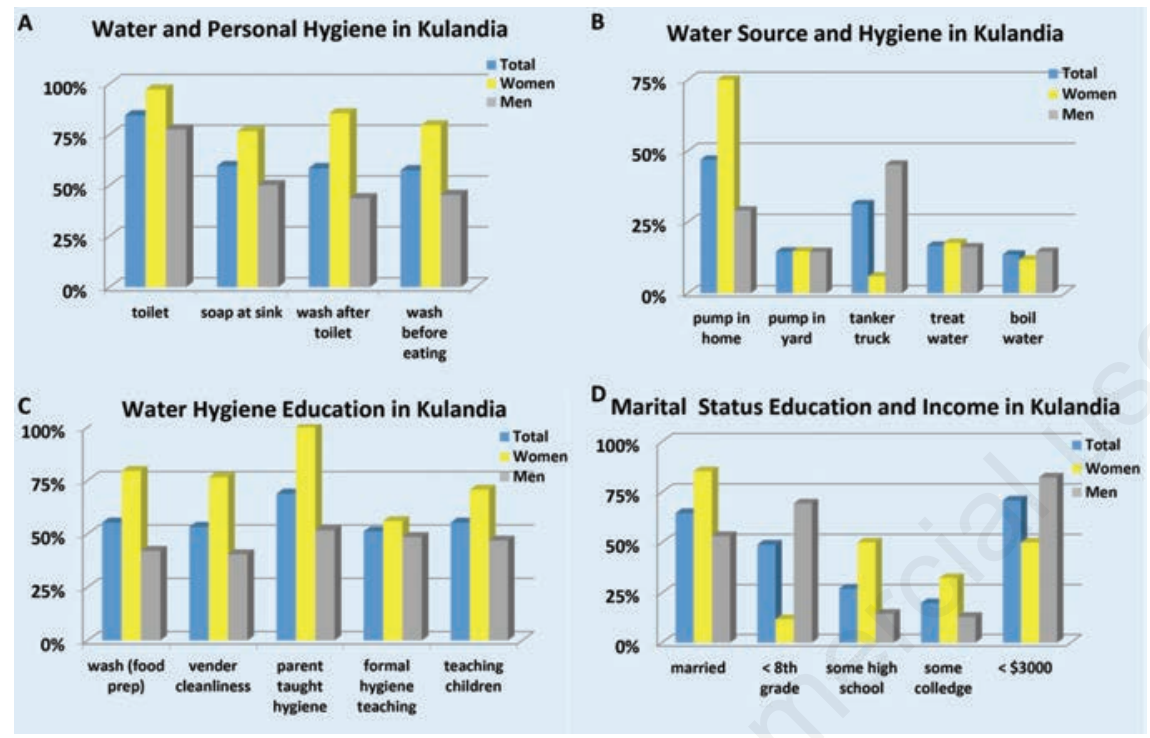

Figure 1. A) demonstrates the distribution of key personal hygiene measures. B) demonstrates the different water sources for study participants. C) displays the distribution of hygiene related education in study participants. D) displays the spread of education in study participants, along with displaying the breakdown by sex of individuals earning less than $\$ 3000$ per year.

Table 3. Odds ratios and $95 \%$ confidence intervals for selected variables.

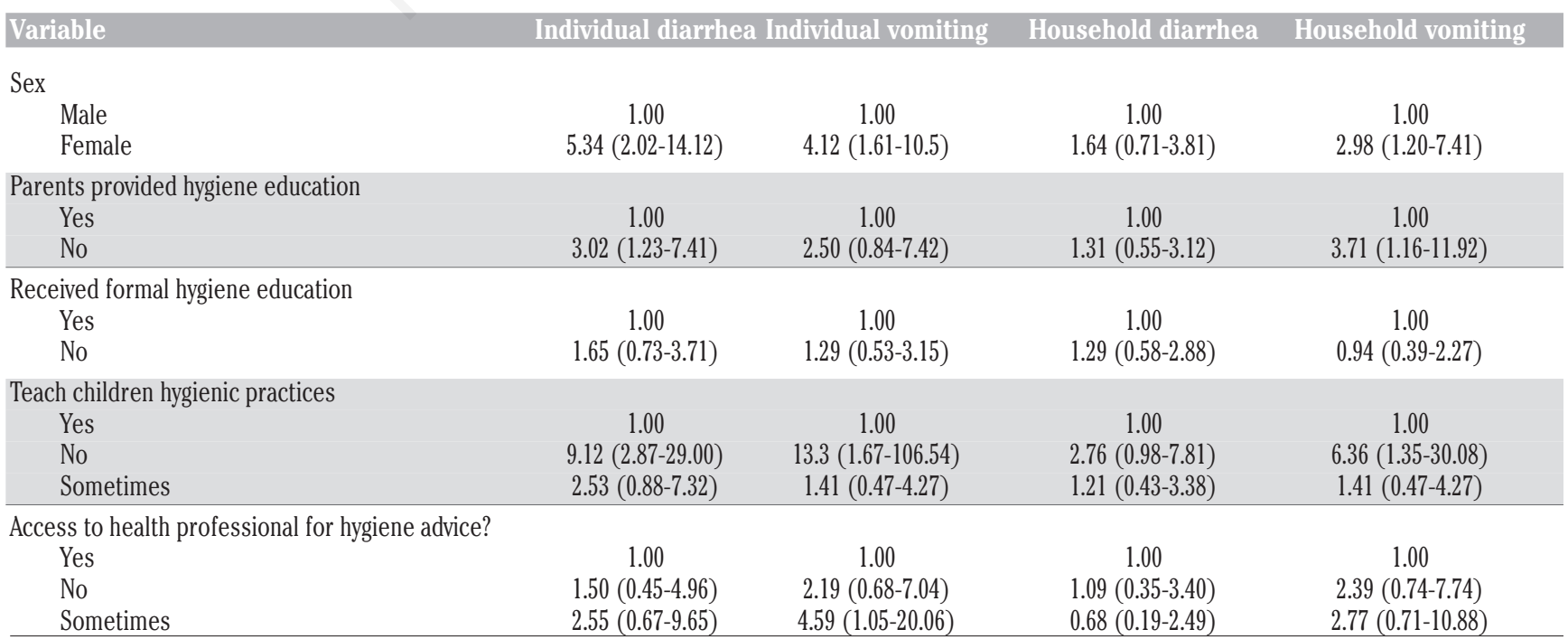

when they were buying food. Regarding water hygiene, piped water was the main source of both drinking and household water (60\%), while a minority utilized tanker-trucks (30\%). Around $45 \%$ of the population did not practice extra water hygiene measures on their household drinking water source. Regarding health hygiene education, $51 \%$ of the study subjects had received formal basic health education regarding personal hygiene (Figure 1C). 68.8 $\%$ of study participants were taught about water hygiene by their parents, but only $55.2 \%$ of the parents are teaching it to their children. Only $15.6 \%$ of study subjects had access to a health professional to ask questions related to hygiene. Although formal, higher education appeared to be protective against emesis $(\mathrm{P}<0.05)$ and diarrheal symptoms $(\mathrm{P}<0.05)$, surprisingly, subjects who had a college education demonstrated higher diarrheal burden relative to subjects who had just a high school

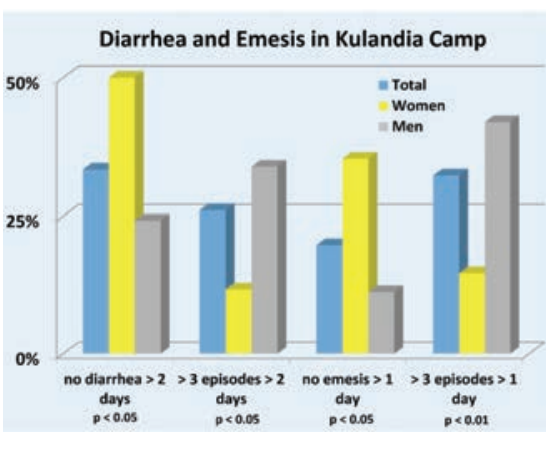

Figure 2. Distribution of emesis and diarrhea in study participants. 
education $\left(\mathrm{P}<0.01 ; 62.5 \%<8^{\text {th }}\right.$ grade, $20 \%$ some or high school grad, $34.8 \%$ some or college grad have 2 or more diarrhea episodes $\geq 2$ days). Having both drinking and household water piped into the house is associated with less diarrhea $(\mathrm{P}<0.05 ; 26.7 \%$ with 2 or more diarrhea episodes for drinking water source piped in dwelling vs. 50\% for tanker-truck).

There was a significant relationship between hygiene practices and GI disease burden. Having soap available at each sink is associated with less diarrhea episodes ( $\mathrm{P}<0.05 ; 31.6 \%$ for yes, $55.6 \%$ for sometimes, $83.3 \%$ for no associated with 2 or more diarrhea episodes). Washing hands after every bathroom use is associated with less diarrhea episodes $(\mathrm{P}<0.005,29.1 \%$ for yes vs. $65.9 \%$ for no), fewer emesis episodes $(\mathrm{P}<0.05)$ and a decreased household burden of GI symptoms (household diarrhea $\mathrm{P}<0.05$; household emesis $\mathrm{P}<0.05)$. Washing hands before eating meals is associated with fewer diarrhea episodes $(\mathrm{P}<0.05 ; 28.6 \%$ for yes vs. $67.5 \%$ for no) and emesis episodes $(\mathrm{P}<0.05)$. Washing hands before preparing meals is associated with fewer emesis $(\mathrm{P}<0.05)$ and diarrhea episodes $(\mathrm{P}<0.05 ; 28.4 \%$ for yes vs. $70 \%$ for sometimes vs. $61.5 \%$ for no).

Basic health education around hygiene was associated with a lower numbers of individual diarrheal and emesis episodes, along with a decrease in household diarrheal burden. Having access to a healthcare professional who can answer questions related to personal hygiene was also associated with fewer individual episodes of diarrhea and emesis, along with a decrease in household diarrheal burden. Receiving formal parental instruction on hygiene practices such as hand washing is associated with fewer diarrhea episodes ( $\mathrm{P}<0.05,36.4 \%$ vs $63.3 \%$ having 2 or more diarrhea episodes) along with a decrease in household emesis burden $(\mathrm{P}<0.05)$. Teaching children about hygiene practices is associated with fewer diarrhea episodes $(\mathrm{P}<0.05,28.3 \%$ for yes vs. $50 \%$ for sometimes $v$ s. $78.3 \%$ for no), emesis episodes $(\mathrm{P}<0.05)$ and a decrease household emesis burden $(\mathrm{P}<0.05)$. Receiving basic non-parental health education is associated with a decrease in household diarrheal burden $(\mathrm{P}<0.05)$, along with a trend of improved individual emesis burden. Factoring in vendor cleanliness when buying food is associated with fewer emesis episodes $(\mathrm{P}<0.01)$, less diarrhea $(\mathrm{P}<0.05,31.4 \%$ for yes vs. $60 \%$ for no) and a decrease in household emesis burden $(\mathrm{P}<0.05)$.

Piped water is protective relative to other forms of household and drinking water sources. Soap availability $(\mathrm{P}<0.05)$, hand wash post restroom use $(\mathrm{P}<0.01)$, hand wash before meal preparations $(\mathrm{P}<0.05)$ and vender cleanness consideration $(\mathrm{P}<0.05)$ all played a protective role in the burden of GI disease. The composite GI score did not result in many statically significant findings, although the results demonstrate trends that are consistent with the above findings.

\section{Discussion}

This is the first study to assess the water and personal hygiene practices at the Kulandia refugee camp. The data highlights the household, familial system of refugees that live in the Kulandia refugee camp. Our results identify a trend of lower GI burden within households with appropriate clean water and sanitation practices (i.e. access to known, clean drinking water source; access to adequate bathroom facilities; availability of soap at the sinks).

Generally, camp residents had access to piped water sources and adequate bathroom facilities. With respect to practices, however, our results show that camp residents would benefit dramatically from basic communal educational initiatives, such as instructions on proper hand washing guidelines and the safe purchase and preparation of food. There are significant hygiene deficits in the camp, which appear to be a product of low formal hygiene education and a limited familial emphasis on hygiene practices. As expected, individuals who employed proper water and personal hygiene practices had lower levels of diarrheal illnesses. The variables and hygiene practices that were associated with lower rates of diarrheal illness included having household and drinking water sources piped into the home, proper hand washing, adequate soap availability, and proper consideration of vendor cleanliness. Additionally, higher income, higher levels of general education, having received formal or parental health hygiene education, participating in educating children on hygiene practices and having access to healthcare professions to discuss hygiene related matters were all generally associated with a decrease in GI burden. The surprising result of college educated individuals having higher burden of diarrhea relative to high school educated subjects is likely related to the low number of study subjects who had a college education.

The study identifies specific areas where lapses in proper water and personal hygiene practice occurs, thus suggesting specific targets for future interventions. If parents had the proper background in adequate personal hygiene practices and spent time with their children developing these skills, one could expect improvements infectious disease prevention, especially among children. Further, incorporating formal hygiene education in UNRWA schools in Kulandia has the potential to have meaningful impacts on the transmis- sion of infectious diseases in the camp. The importance of these interventions are highlighted when considering the established relationship between poor personal hygiene and disease burden in the Kulandia refugee camps. Such interventions represent cheap, simple actions that could improve the general health outcomes of refugees living in Kulandia within a relatively short time frame.

However, there are barriers to quickly and effectively implementing such interventions. Our data shows that camp residents have highly limited access to health professionals with whom they can discuss issues of health hygiene. Additionally, Kulandia has many infrastructural limitations that highlight the importance of maximizing individual water and personal hygiene practices. The insufficient sewage system with frequent leaks, use of cesspits by some households, inadequate handling of wastewater and generally poor camp conditions highlight the structural obstacles faced by camp residents in their attempts to prevent infectious disease. The context of the current political situation between Israel and the Palestinians explains the difficulty in addressing these infrastructural limitations.

There were limitations to the study. Several of the statically significant relationships seen with individual analysis of symptoms were lost when using the rough composite indicator of composite GI score. This is most likely due to the limited power in this study, as the trends in the data revealed similar findings. Most of the study participants were recruited from the Kulandia health clinic, thus representing individuals who likely would access healthcare professions. This could result in a biased study sample that overestimates the water and personal hygiene practices that actually exist in the refugee camp. This limitation would results in a loss of significant relationships; further highlighting the benefits of a community education program. Further, given that these subjects were recruited from a healthcare clinic, they may have more underlying health conditions that might make them more vulnerable to symptomatic GI infections.

\section{Conclusions}

The authors have identified target areas where population-based educational programs could improve the health of individuals living in the Kulandia Palestinian refugee camp. The authors highlight the consistencies of established health associations between safe water and personal hygiene education and practices with respect to GI disease burden in the quasipermanent Palestinian refugee population and encourage further research in Palestinian refugee population health. Maximizing con- 
trollable individual health practices, such as water and personal hygiene, are cost effective measures that could assist Kulandia residents in overcoming health obstacles that are a direct results of the living conditions at the camp.

\section{References}

1. Riccardo F, Khader A, Sabatinelli G. Low infant mortality among Palestine refugees despite the odds. Bull World Health Organ 2011;89:304-11.

2. Alabed S, Guul A, Crighton C, et al. An assessment of diabetes care in Palestinian refugee camps in Syria. Avicenna J Med 2014;4:66-70.

3. Habib RR, Hojeij S, Elzein K, et al. Associations between life conditions and multi-morbidity in marginalized populations: the case of Palestinian refugees. Eur J Public Healt 2014;24:727-33.

4. Zabaneh JE, Watt GCM, O'Donnell CA. Living and health conditions of Palestinian refugees in an unofficial camp in the Lebanon: a cross-sectional survey. $\mathrm{J}$
Epidemiol Commun Health 2008;62:91-7.

5. Bocco R. UNRWA and the Palestinian refugees: a history within history. Refug Surv Q 2010;28:229-52.

6. Canadians for Justice and Peace in the Middle East. Factsheet: UNRWA, History and Context; 2010. Available from: http://www.cjpmo.org/DisplayDocument.as px?DocumentID=633

7. Al-qudsi SS. Profiles of refugee and nonrefugee Palestinians from the West Bank and Gaza. Int Migr 2000;38:79-107.

8. Clements A, Rionda Z. The burden of disease in the West Bank and Gaza, an assessment report. 2000. Available form: http://pdf.usaid.gov/pdf_docs/Pnacj994.pdf

9. Prüss-Üstün A, Corvalán C. Preventing disease through healthy environments: towards an estimate of the environmental burden of disease. 2006. Available from: http://www.who.int/quantifying_ehimpacts/publications/preventingdisease.pdf

10. OCHA. Kalandia Refugee Camp Profile. http://www.ochaopt.org/documents/opt_ca mpprof_unrwa_qalandia_oct_2008.pdf

11. Palestinian Localities Study, Jerusalem Governorate. Qalandiya camp profile. 2012. http://vprofile.arij.org/jerusalem/
pdfs/vprofile/Qalandiya\%20Camp_EN.pdf

12. UNRWA. Camp profiles. Available from: http://www.unrwa.org/where-wework/west-bank/camp-profiles?field=12. Accessed July 3, 2014.

13. Lilienfield LS, Rose JC, Corn M. UNRWA and the health of Palestinian refugees. United Nations Relief and Works Agency. N Engl J Med 1986;315:595-600.

14. Prüss-Ustün A, Bartram J, Clasen T, et al. Burden of disease from inadequate water, sanitation and hygiene in low- and middleincome settings: a retrospective analysis of data from 145 countries. Trop Med Int Healt 2014;19:894-905.

15. Beuer R, Bloomfield S. Hygiene procesudres in the home and their effectiveness: a review of the scientific evidence base. 2008 Available from: http:/www.ifh-homehygiene.org/best-practice-review/hygieneprocedures-home-and-their-effectivenessreview-scientific-evidence-base.

16. Illinois Department of Public Health. Foodand water-borne illnesses. Available from: http:/www.idph.state.il.us/Bioterrorism/fa ctsheets/food_water_borne.htm. 